\title{
Estudo Bibliográfico sobre o Processo de Construção de Jogos Digitais: A Necessidade de Sinergia entre o Educar e o Divertir
}

Title: Bibliographical Study on Digital Games Building Process: The Need for Synergy between Educating and Fun

Kenia Kodel Cox

Universidade Federal de Sergipe

kenia@dcomp.ufs.br

\author{
Roberto Almeida Bittencourt \\ Universidade Estadual de Feira de Santana \\ roberto@uefs.br
}

\begin{abstract}
Resumo
Segundo estatísticas, 179 milhões de pessoas, o correspondente a 61\% da população mundial on-line, fazem uso de jogos digitais; e estes, conforme pesquisas, podem conduzir seus usuários a condições favoráveis de aprendizagem, o que pode tornar esses jogos ferramentas de ensino viáveis. Porém, estudos sinalizam que os jogos educativos não têm sido projetados usando alicerces científico-metodológicos apropriados; e assim tem-se obtido, ou jogos divertidos com baixo potencial educativo; ou jogos que educam sem divertir, elou motivar. Considerando o exposto, neste trabalho tem-se como objetivo investigar como promover a sinergia entre diversão e a educação na construção de jogos educativos. Para tanto busca-se respostas nos recortes que permeiam a criação de um game: o que os caracterizam, seus tipos, o que motiva os jogadores, e o processo de construção destes.
\end{abstract}

Palavras-Chave: jogos; construção de jogos educativos; ludicidade; educação; ferramentas educacionais

\begin{abstract}
According to statistics, 179 million people, 61\% of the online mundial population, use digital games. According to research, games can lead their users to favorable learning conditions, which may turn them into viable teaching tools. However, studies suggest that educational games have not been designed according to coherent scientific and methodological foundations. Hence, industry and community are producing either fun games with low educational potential or games that educate without amusing, and/or motivating. Considering the above, this work has the objective of investigating how to promote synergy the fun and education in the construction of educational games. To this end we seek to answer the cutouts that permeate the creation of a game: what characterizes them, their types, which motivates players, and their construction process.
\end{abstract}

Keywords: games; educacional games development; ludicity; education; educational tools

Cite as: Cox, K. K.. \& Bittencourt, R. A. (2017). Bibliographical Study on Digital Games Building Process: The Need for Synergy between Educating and Fun (Estudo Bibliográfico sobre o Processo de Construção de Jogos Digitais: A Necessidade de Sinergia entre o Educar e o Divertir). Brazilian Journal of Computers in Education (Revista Brasileira de Informática na Educação - RBIE), 25(1), 16-43. DOI: 10.5753/RBIE.2017.25.01.16 


\section{Introdução}

Segundos dados estatísticos, o número de utilizadores de jogos digitais corresponde hoje a 179 milhões de pessoas, o que equivale a $61 \%$ da população mundial on-line, de 110 países ao redor do mundo. E os games, ao mesmo tempo que entretêm, podem ser aplicados como instrumentos educativos, Neto e Alves (2010).

De acordo com Conolly, Boyle, MacArthur, Hainey e Boyle (2012): "As teorias contemporâneas educacionais eficazes sugerem que a aprendizagem é mais efetiva quando é ativa, experiencial, contextualizada, baseada em problemas e provê feedback imediato. E jogos oferecem atividades que têm todas estas características".

Um jogo digital educacional pode ser entendido como um software que tem bem definidos objetivos próprios de educação: motiva os alunos para os estudos, promove a aprendizagem; isto por meio de atividades de diversão, ou seja, prazerosas e desafiadoras Savi, Von Wangenheim e Borgatto (2011), Lopes, Marques e Conte (2012), Põtter e Schots (2012), Merelles, Peixoto e Monsalve (2011), e assim, apresenta como requisitos possibilidades de efetuar testes de hipóteses, ou resolução de problemas geralmente complexos, e não se limita à simples memorização, Paraskeva, Mysirlaki e Papagianni (2010) e Mendes (2011).

Percebe-se que a importância cognitiva destes jogos reside na diversidade de pesquisas indicativas de que muitos deles desenvolvem habilidades indispensáveis ao processo de aprendizagem: atenção, concentração, orientação espacial, resolução de problemas, tomada de decisões, trabalho colaborativo, criatividade e outros.

Vale ainda destacar que estudos sobre a aplicação de jogos como ferramentas educacionais consideram que estes integram as dimensões da personalidade de seus usuários: afetiva, motora, cognitiva e social, Gularte \& Alves (2011), que devem ser considerados como estratégia de ensino Savi, Von Wangenheim e Borgatto (2011), Paraskeva et al. (2010), Mendes (2011) e Souza-Concílio e Pachaco (2013) além de conduzir os jogadores a condições favoráveis de aprendizagem - satisfação, desejo Paraskeva et al. (2010), desafio, interesse, divertimento e orgulho em realização.

Schmitz, Klemke e Specht citado por Fadel, Ulbricht e Batista (2014), “destacam que [...] personagem, competição e regras de jogos - são necessários quando a gamificação é aplicada a contextos de ensino, com efeito direto no processo de aprendizagem do indivíduo. Como exemplo: o personagem permite a identificação com o estudante; a competição favorece o foco e a atenção dos alunos; e as regras do jogo propiciam um ambiente de imersão favorável ao envolvimento do estudante no contexto de aprendizagem" (Fadel, Ulbricht e Batista, 2014, p. $88)$.

Porém, a abordagem de game design onde os jogos educacionais são projetados com prioridade para a diversão e a jogabilidade, enquanto os conteúdos educacionais ficam em segundo plano, é ineficiente, pois assim obtém-se jogos com déficit no estímulo ao aprendizado, apesar da diversão e imersão, Mendes (2011).

Também quando o aspecto entretenimento apresenta falha em um projeto de jogo educativo, muitas das vantagens de aprendizagem baseadas nestes, em especial em termos de motivação e adequação, são perdidas, e a aprendizagem sofre prejuízos devido principalmente à ausência do engajamento e da motivação instigados pela diversão.

Logo, faz-se necessários haver sinergia entre os elementos de diversão e os de educação contidos num jogo digital educacional. 
Mendes (2011) e Conolly et al (2012) argumentam que jogos educacionais não têm sido projetados usando alicerces científico-metodológicos apropriados.

A partir destas considerações, é possível concluir que há lacunas nas pesquisas acerca de como equilibrar educação e diversão em projetos voltados para construção de jogos digitais educativos, o que justifica a presente iniciativa.

Assim, considerando o número de pessoas que são usuários de games, o potencial educacional destes e os déficits supracitados, neste busca-se investigar, através de pesquisa com objetivo exploratório e procedimentos de revisão bibliográfica, alguns recortes teóricos de composição do processo de construção de jogos educativos, a saber: (a) formas de aplicação de jogos na educação; (b) bases teóricas; (c) elementos de composição; (d) gêneros; (e) motivação dos jogadores; e (f) processos de construção; buscando evidências acerca de como equilibrar a diversão e a educação no processo de criação de jogos educacionais, de forma a extrair destes o máximo de seu potencial educativo. Tais recortes correspondem às próximas seções do presente trabalho.

\section{Formas de Aplicação de Jogos na Educação}

Duas principais formas de aplicação de jogos digitais na educação foram identificadas: (1) jogos educativos e (2) jogos de entretenimento.

Há ainda a forma de aplicar jogos na educação estimulando alunos a construírem seus próprios games. Uma iniciativa neste sentido é o "Scratch" que possibilita aos seus usuários criarem seus próprios jogos e animações, e os compartilharem com outros membros da comunidade on-line. A aprendizagem ocorre porque o aluno precisa efetuar pesquisas sobre o tema do jogo, idealizá-lo, aprender e aplicar recursos do "Scratch", e sente motivação pelo produto obtido e pela apreciação de seus pares.

Rodrigues, Zem-Lopes, Marques e Isotami (2015), sobre a exploração dos recursos dos Scratch, destaca “[...] a possibilidade de estimular o raciocínio lógico e a resolução de problemas de forma lúdica e dinâmica, além do desenvolvimento de noções básicas de programação".

E também existe os Sistemas de Gerenciamento de Aprendizagem, ou (LMS) ${ }^{2}$ que podem ser compreendidos como um espaço de distribuição de informação, onde se estabelece negociação coletiva permanente, respeitando, assim, a multiplicidade de olhares e referências, e por consequência, estimulando a aprendizagem.

A proposta de implementação de LMS mediados por jogos eletrônicos possibilita a criação de novos espaços de aprendizagem que rompem com a linearidade, mediado pelos recursos dos games; e assim constrói-se uma prática pedagógica através ensino à distância, extrapolando a transposição das práticas de ensino presenciais para as on-line.

\subsection{Jogos Educativos}

Um exemplo de jogo educativo, é o "Comilo-Saurus", uma iniciativa do grupo Ludo Educativo,

\footnotetext{
1 Projeto do grupo Lifelong Kindergarten no Media Lab do MIT, fornecido gratuitamente, disponível em http://scratch.mit.edu/, acessado em 27/04/2014.

Correspondente a Learning Management System - LMS.
} 
e resultado da parceria entre o $\mathrm{CDMF}^{3}$, da Fapesp ${ }^{4}$, e o INCTMN/CNPq ${ }^{5}$.

No "Comilo-Saurus", o objetivo educacional refere-se à alimentação balanceada e diferenças entre dietas dos animais. E para garantir diversão há a narrativa de que bebês dinossauros viajam no tempo e chegam ao laboratório de uma cientista. Enquanto ela calibra a máquina que os mandará de volta ao passado, o jogador precisa manter os bebês bem alimentados, com equilíbrio de carboidratos, proteínas, vitaminas e gorduras - caso contrário, o lugar pode ser devorado pelos filhotes.

Outro exemplo de jogo educativo é "EDUCPLAY”, Mota e Alencar (2015), através do qual o aluno deve identificar vogais e caçar palavras; desenvolvido para "ajudar no letramento infantil, considerando que os alunos podem aprender de formas diferentes e com atividades bem mais divertidas e atrativas [...]" (Mota \& Alencar, 2015, p. 8).

Quadro 1: Jogos Educativos Aplicados na Educação.

\begin{tabular}{|c|c|}
\hline Pesquisas & Jogos Educativos Aplicados na Educação \\
\hline $\begin{array}{c}\text { Lopes et al. } \\
(2012)\end{array}$ & Tratam do jogo "InspSoft", para o ensino de inspeção de software. \\
\hline $\begin{array}{c}\text { Andrade e Alves } \\
(2011)\end{array}$ & $\begin{array}{c}\text { Falam do ensino acerca da fundação de Salvador, da independência da Bahia, dentre outros } \\
\text { assuntos; através do jogo intitulado "Lukas James e os Viajantes da História" }\end{array}$ \\
\hline $\begin{array}{c}\text { Pires, Navarro e } \\
\text { Pires (2015) }\end{array}$ & $\begin{array}{c}\text { Apresentam o jogo "Mr. Data Analyst", que simula situações em que um analista de dados } \\
\text { se depara com diferentes cenários nos quais deve identificar possíveis problemas que afetam } \\
\text { a qualidade de dados armazenados em bancos de dados relacionais. }\end{array}$ \\
\hline $\begin{array}{c}\text { Matsunaga, } \\
\text { Borges e Maraes } \\
(2015)\end{array}$ & $\begin{array}{c}\text { Desenvolvem um jogo educativo para crianças com hemofilia, que reforça conceitos e } \\
\text { atitudes adequadas frente às diversas situações de vida enfrentadas desde a infância pelos } \\
\text { mesmos. }\end{array}$ \\
\hline $\begin{array}{c}\text { Filho, Costa e } \\
\text { Dominguez } \\
(2015)\end{array}$ & $\begin{array}{c}\text { "Sim Investigador" corresponde a um jogo digital educativo aberto que explora histórias } \\
\text { sobre o conteúdo a ser ensinado. O jogador pode assumir o papel de um investigador, ou } \\
\text { construindo casos, que são narrações que contextualizam um assunto no universo do jogo; } \\
\text { ou resolvendo um caso interagindo na história e resolvendo questões. }\end{array}$ \\
\hline
\end{tabular}

São inúmeras as iniciativas acadêmicas voltadas para jogos educativos, exemplos são descritos no Quadro 1.

Nos jogos educativos, o conteúdo pedagógico é embutido nos elementos de composição do game: na narrativa, na jogabilidade, nos personagens, na interface, nos níveis; de forma que o assunto seja aprendido de maneira prazerosa e divertida.

\subsection{Jogos de Entretenimento}

Há jogos desenvolvidos sem contemplar a possibilidade de uso educacional, mas que apresentam conteúdos e modelos tão ricos em informações e detalhes que podem ser usados para o ensino. É o caso, por exemplo, dos jogos "Civilization" e "Angry Birds Rio".

Segundo Lopes (2011):

“[...] os professores estão explorando de forma direta os jogos comerciais. Kurt Squire [...] estudou a integração do jogo "Civilization III" à sala de aula. Em suas experiências, os alunos foram capazes de apreender conceitos como 'monarquia', 'metalurgia' e 'monoteísmo', além de identificar sua influência no desenrolar do processo histórico" (Lopes, 2011, p. 88).

Centro de Pesquisa para o Desenvolvimento de Materiais Funcionais.

Fundação de Amparo à Pesquisa do Estado de São Paulo.

Instituto Nacional de Ciência e Tecnologia dos Materiais em Nanotecnologia. 
Outro exemplo é o jogo "Angry Birds Rio" que trata de um grupo de pássaros, furiosos por terem sido capturados e enviados por contrabandistas ao Brasil. Ao chegarem, encontram outras aves aprisionadas em gaiolas. Em cada fase do game, os pássaros furiosos, usando estilingue, se lançam nessas gaiolas na tentativa de destruí-las, e, assim, salvar as outras aves.

Com a aplicação do citado jogo de entretenimento podem ser trabalhadas, por exemplo, "[...] razões trigonométricas, a partir de triângulos formados pelos pontos de lançamentos dos pássaros; e funções do segundo grau, reconhecida pelo formato de parábola gerado pela trajetória do pássaro quando lançado [...]” (Moita, Luciano \& Costa, 2013, p. 123).

Quadro 2: Jogos de Entretenimento Aplicados na Educação

\begin{tabular}{|c|c|}
\hline Pesquisas & Jogos de Entretenimento Aplicados na Educação \\
\hline $\begin{array}{c}\text { Morais e } \\
\text { Mendes (2013) }\end{array}$ & $\begin{array}{l}\text { Afirmam que através de jogos de videogames sobre esporte, podem ser trabalhadas, com } \\
\text { alunos de Educação Física, informações sobre a cultura do espetáculo esportivo sobre regras } \\
\text { e táticas. E ainda os "sentidos e valores sobre as disputas humanas, fora as sensações } \\
\text { diversas do entretenimento virtualizado". }\end{array}$ \\
\hline $\begin{array}{l}\text { Moita, Luciano } \\
\text { e Costa (2013) }\end{array}$ & $\begin{array}{l}\text { Ao relatarem a aplicação do jogo de entretenimento “Angry Birds Rio", informam que: “A } \\
\text { [...] contextualização como fator facilitador da compreensão de conceitos matemáticos } \\
\text { justifica a utilização de recursos inerentes ao cotidiano dos alunos. [...] Para tal, a escola vem } \\
\text { se valendo de [...] jogos [...]." }\end{array}$ \\
\hline $\begin{array}{l}\text { Araujo, Leal e } \\
\text { Evangelista } \\
\quad(2014)\end{array}$ & $\begin{array}{l}\text { Tratam do "Simcity" que oportuniza a exploração de vários temas e conceitos básicos de } \\
\text { geografia com ludicidade; "por meio do que é possível criar, planejar, construir e } \\
\text { gerenciar cidades, simulando e visualizando cenários urbanos resultantes das } \\
\text { diversas formas de intervenção humana, instigando a reflexão sobre a visão de } \\
\text { mundo e de geografia subjacente a essas intervenções" (Araujo, Leal \& Evangelista, 2014, } \\
\text { p. 88). }\end{array}$ \\
\hline $\begin{array}{c}\text { Cechin, Trois \& } \\
\text { Silva }(2012)\end{array}$ & $\begin{array}{l}\text { Para Biz citado por Cechin et al. (2012), ao relatar o uso do jogo comercial "Puzzle Quest", } \\
\text { "o RPG funciona, como ferramenta para preparar o jovem a interagir na sociedade, tanto } \\
\text { profissional quanto socialmente. Algumas empresas utilizam o RPG para treinamento de } \\
\text { pessoal, uma vez que a premissa básica do jogo é a simulação da realidade. }\end{array}$ \\
\hline
\end{tabular}

No Quadro 2 são elencadas pesquisas que corroboram com a aplicação de jogos de entretenimento na educação.

Entretanto, através de revisão sistemática, Conolly et al (2012) constataram que "poucos exemplos de jogos de entretenimento sendo explicitamente utilizados em sala de aula foram encontrados, principalmente devido a dificuldades em combinar as qualidades de jogos de entretenimento com as especificidades curriculares almejadas".

Ao tratar especificamente da aprendizagem e da diversão, nota-se que uma alternativa para obtenção de equilíbrio entre os dois extremos é trabalhar com os jogos de entretenimento existentes explorando o valor educacional destes bem como, quando possível, adaptando sua implementação para reduzir os custos para obtenção de jogos voltados para a educação.

A adaptação de jogos educativos visa ampliar os resultados obtidos a partir da aplicação de games educacionais pré-existentes, ou seja, ampliar a abrangência dos conteúdos de ensino destes, enriquecendo a experiência de aprendizagem que oferecem aos jogadores, por exemplo, a partir da adaptabilidade e personalização dos jogos.

\subsection{Considerações}

A familiaridade e a relação prazerosa existente entre aprendizes e games, aliada ao potencial educativo destes, justifica as iniciativas de aplicação de jogos como ferramentas educacionais.

Neste contexto, surgem jogos educativos e LMS com aplicação de dinâmica de jogos que educam enquanto divertem; porém apresentam processo de construção dispendioso. Então surgem as outras propostas: de aplicação de jogos comerciais de entretenimento e adaptação de 
games pré-existentes; com a vantagem de terem menor custo, entretanto com limitações no processo de criação, já que dependem dos recursos que constam no jogo a ser adaptado.

\begin{tabular}{|c|l|l|}
\hline $\begin{array}{c}\text { Formas de Aplicação de } \\
\text { Jogos na Educação }\end{array}$ & \multicolumn{1}{|c|}{ Custo $^{6}$} & \multicolumn{1}{c|}{ Benefício $^{7}$} \\
\hline $\begin{array}{c}\text { Com Jogos } \\
\text { Educativos }\end{array}$ & $\begin{array}{l}\text { Máximo. Custos com profissionais de arte, de } \\
\text { educação, de game design, de engenharia de } \\
\text { software; bem como com as ferramentas. }\end{array}$ & $\begin{array}{l}\text { Máximo. Jogo que disponibiliza } \\
\text { componentes totalmente conforme } \\
\text { idealizado, dedicados aos objetivos } \\
\text { almejados. }\end{array}$ \\
\hline $\begin{array}{c}\text { Com LMS } \\
\text { Com Jogos }\end{array}$ & $\begin{array}{l}\text { Mínimo. Custo para identificar um jogo } \\
\text { comercial com riqueza de detalhes que sirva } \\
\text { como conteúdo educacional. }\end{array}$ & $\begin{array}{l}\text { Médio. O jogo resultante não tem } \\
\text { todos os componentes como } \\
\text { idealizados, já que é pré-existente. }\end{array}$ \\
\hline $\begin{array}{c}\text { Com Adaptação de } \\
\text { Jogos }\end{array}$ & $\begin{array}{l}\text { Médio. Aproveita-se parte dos elementos de } \\
\text { composição de jogo pré-existente. }\end{array}$ \\
\hline
\end{tabular}

Quadro 3: Custo e Benefício das Formas de Aplicação de Jogos na Educação.

Considerando o exposto, nota-se que a aplicação de jogos na educação pode ser efetuada de diversas formas, o que requer dos responsáveis por iniciativas como estas, a avaliação da proposta que melhor se adequa ao seu contexto de aplicação. Para tanto, ver Quadro 3.

\section{Bases Teóricas dos Jogos Digitais Educacionais}

Em estudos voltados para aplicação de jogos digitais na educação, dois principais tipos de bases teóricas se destacam: de aprendizagem e motivacionais.

\section{De Aprendizagem:}

Construtivismo Filho et al. (2015), Gularte \& Alves (2011), Souza-Concílio e Pachaco (2013), Haworth e Sedig (2011) - que considera que aprendizagem ocorre a partir de construções individuais de conhecimento obtidas através de interações com o ambiente e/ou a cultura Gularte \& Alves (2011).

Construcionismo Filho et al. (2015), Souza-Concílio e Pachaco (2013) - considera que o projeto e implementação de produtos de interesse pessoal dos alunos despertam a autonomia e a iniciativa destes, promovendo a aprendizagem, Filho et al. (2015).

Behaviorismo Gularte \& Alves (2011), Souza-Concílio e Pachaco (2013) - parte do pressuposto de que a aprendizagem ocorre por condicionamento, por tentativa e erro.

Aprendizagem Significativa Mendes (2011), Moita et al. (2013) - defende que o jogador amplia seus conhecimentos associando-os a conceitos pré-existentes em sua bagagem cognitiva.

\section{Motivacionais:}

Teoria do Fluxo Souza-Concílio e Pachaco (2013), Alves e Battaiola (2011) - propõe diretrizes para gerar situações que motivam a aprendizagem, dentre as quais destacam-se: despreocupação com o controle e com o erro e feedback imediato.

Taxonomia de Malone e Lepper Souza-Concílio e Pachaco (2013), Alves e Battaiola (2011)

Custo definido em comparação às outras formas de aplicação de jogos na educação apresentadas. Benefício definido em comparação às outras formas de aplicação de jogos na educação apresentadas. 
- que tem como pilares: (a) o desafio - fator instigante, (b) a fantasia - para alcançar o emocional, (c) a curiosidade - despertada por meio do apelo visual e (d) o controle - para possibilitar a autonomia sobre o objeto em estudo.

Modelo ARCS Lopes et al. (2012), Gularte \& Alves (2011), Souza-Concílio e Pachaco (2013) - aponta quatro pilares que podem motivar o aluno a aprender: atenção, relevância, confiança e satisfação.

Outras bases teóricas usadas na construção de jogos digitais educativos são: Teoria da Atividade Paraskeva et al. (2010) e, bem como a Taxonomia de Bloom Savi et al. (2011), Lopes et al. (2012), Gularte \& Alves (2011) - aplicada inicialmente para planejar e projetar aprendizagem; considera que há seis níveis de raciocínio: (1) conhecimento - situação inicial da aprendizagem; (2) compreensão - quando ocorre interpretação e extrapolação do conhecimento; (3) aplicação - conhecimentos são aplicados em situações concretas; (4) análise - efetuada em três partes: elementos, relações e princípios; (5) síntese - correspondente à combinação de partes não organizadas para formar um todo e (6) avaliação - quando se julga o valor do conhecimento.

\subsection{Considerações}

Por se tratar de jogos educativos, havia de se pressupor que as bases teóricas fossem estritamente educacionais, no entanto não é o que de fato se constata; e a justificativa reside justamente no cerne da questão levantada nesse estudo - é preciso haver equilíbrio entre educação e diversão. Assim, observa-se dentre as bases teóricas dos jogos digitais educacionais, algumas que tiveram origem na psicologia, outras especificamente voltados para motivação e que na prática beneficiam a aprendizagem, e desenvolvimento humano; e que são efetivamente aplicadas na concepção, definição da mecânica ${ }^{8}$, jogabilidade, testes de protótipos do processo de desenvolvimento, e na avaliação de games educativos.

É válido ainda ressaltar que não há convergência por parte dos pesquisadores quanto às bases teóricas que alicerçam a construção de jogos digitais educacionais. Observa-se que tais bases são: construtivismo ${ }^{9}$, construcionismo ${ }^{10}$ e a cognição situada ${ }^{11}$; enquanto que "[...] para se criar uma ferramenta educacional, deve-se escolher que modelo de educação é mais adequado para o problema proposto [...]" (Gularte \& Alves, 2011, p. 3), e optam pelo behaviorismo para desenvolvimento de jogo voltado para o contexto empresarial. De fato, não há uma base educacional que atenda a todas as necessidades de aplicação de jogos. Enquanto jogos voltados para o treinamento de pilotos, por exemplo, priorizam o condicionamento; games de estratégia estimulam prioritariamente a criatividades; logo devem fundamentar-se em alicerces teóricos distintos.

Assim, vale ainda considerar que estas teorias não esgotam as bases que podem ser aplicadas na construção de jogos educativos, podendo os desenvolvedores de games elegerem a teoria que julgarem mais adequada aos objetivos educacionais e de entretenimento almejados;

\footnotetext{
8 Definição do que os jogadores devem fazer para alcançar o objetivo central do jogo: tomada de decisões, geração de recursos, lutar, cumprir orientações.

A teoria educacional construtivista se concentra no desenvolvimento do conhecimento e compreensão profunda, ao invés de comportamentos ou habilidades, como metas de aprendizagem, Morais e Mendes (2013).

Para a abordagem construcionista, aprender envolve duas atividades: a construção do conhecimento através da experiência e da criação de produtos pessoalmente relevantes .

11 Cognição Situada - Situated Cognition - é a teoria que postula que o conhecimento é inseparável do fazer, argumentando que todo o conhecimento é situado em atividade vinculada aos contextos sociais, culturais e físicos, Morais e Mendes (2013).
} 
entretanto é indispensável aplicar uma teoria de estímulo à aprendizagem, já que se almeja construir uma ferramenta educacional, sem jamais perder de vista a necessidade de garantir a diversão, possivelmente por meio da aplicação de uma teoria motivacional.

\section{Elementos de Composição}

Os jogos digitais educacionais devem ser compostos pelos elementos que garantem a ludicidade dos games digitais, com a adaptação destes e a adição de outros componentes para estimular a educação.

Na presente pesquisa, o trabalho de Novak (2010) foi usado como framework para organizar o conhecimento, e para identificação dos elementos que garantem o aspecto lúdico dos games de propósito geral; isto porque a citada autora apresenta larga experiência sobre o assunto, tanto acadêmica quanto comercial; e na referida obra apresenta relatos de experientes profissionais da área de game design. Já os aspectos educacionais dos jogos, foram colhidos a partir de artigos científicos. Assim, este trabalho busca estabelecer uma aproximação entre os conhecimentos para desenvolvimento de jogos de propósito geral com os de caráter educativo, de maneira a obter games que educam sem perder seu caráter divertido.

Os jogos digitais são compostos por cinco elementos principais Novak (2010): narrativa que pode garantir o envolvimento emocional e a imersão do jogador, e assim servir de motivação para este; personagens - que possibilitam ao jogador identificar-se com o jogo e atuar neste; jogabilidade - tarefas, opções, desafios e consequências que confrontam os jogadores durante o game; níveis - que podem inserir um novo objeto ou personagem, revelar um aspecto da narrativa, modificar o cenário do jogo, alterando o grau de dificuldade; e interface - que garante a coesão entre o jogador e o game, possibilitando que o jogo forneça as informações necessárias para o usuário jogar, bem como os recursos para que este execute outras ações que precisar.

\subsection{Narrativa}

A estrutura narrativa conhecida como roteiro em três atos, é usada na construção de jogos digitais Andrade e Alves (2011), Novak (2010). Neste há o começo, ou ato I, que tem por objetivo capturar a atenção dos usuários; o meio, ou ato II, que se trata da tensão narrativa; e o fim, ou ato III, quando ocorre a resolução do problema.

A narrativa, independente da sua estrutura, seja em três atos, ou outra, pode ser composta por:

História - onde há: (a) a premissa - resumo com a finalidade e o tema geral do game; (b) história anterior - o que ocorreu antes do início do jogo, que orienta o jogador quanto à finalidade e tipo de ação deste, e possibilita que o usuário se vincule a algum personagem; (c) sinopse - a história em construção, o que auxilia o jogador a imergir no mundo do game; (d) tema - conceitos e valores trabalhados pela história; (e) cenário - representação do contexto onde a história ocorre.

Enredo - é formado pelo: (a) equilibrio entre conflitos - entre os desafios e a superação destes, pois excesso de conflitos desestimulam pelos fracassos, e de facilidades desestimulam pela monotonia; (b) mudança de foco - ao adicionar-se tarefas, ou personagens, ou objetos, proporcionando quebras de tensões; (c) prenúncio de eventos - para estimular expectativas; (d) suspensão de descrença - para fazer o jogador distanciar-se da vida real e imergir na realidade artificial proposta pelo jogo; (e) realismo - contrário à suspensão de descrença, visa imitar o mundo real com o máximo de fidelidade. 
Nos jogos digitais há, de forma exclusiva, certos elementos na narrativa: (a) interatividade - os usuários devem abandonar a postura de mero expectador, e interagir; (b) não linearidade presente nos games devido a liberdade de escolhas dadas aos usuários; (c) controle pelo jogador - através da personalização dos personagens, escolha de caminhos, construção de mundos, comunicação com outros jogadores, e outros; (d) colaboração - mais evidente em jogos onde múltiplos jogadores podem atuar em grupo; e (e) imersão - quando os jogadores sentem-se distantes de seu contexto real e presentes no ambiente virtual do jogo.

Pesquisas que consideram a narrativa como elemento de composição dos jogos digitais são apresentadas no Quadro 4.

As narrativas dos jogos eletrônicos podem ser usadas como recurso de imersão, possibilitando que o jogador seja estimulado a participar do universo e da dinâmica do jogo; bem como como ferramental através do qual são apresentadas informações acerca do conteúdo educacional, no caso de game educativo; logo funciona como um instrumento para a aprendizagem e reflexão em torno dos mais variados temas a serem abordados.

Quadro 4: Composição de Jogos Digitais com Narrativas

\begin{tabular}{|c|c|}
\hline Pesquisas & Composição de Jogos Digitais com Narrativas \\
\hline Audi (2011) & $\begin{array}{l}\text { Afirma que "[...] uma narrativa bem feita compensa restrições procedimentais e de interface } \\
\text { devido, entre outros fatores, ao vínculo afetivo que cria" (Audi, 2011, p. 8) }\end{array}$ \\
\hline Novak (2010) & $\begin{array}{l}\text { Informa que a narrativa de um game "[...] desempenha um papel significativo naquilo que é } \\
\text { conhecido como imersão, situação em que a história, os personagens e o modo de jogar são tão } \\
\text { poderosos e absorventes que os jogadores envolvem-se profundamente no mundo do game." }\end{array}$ \\
\hline $\begin{array}{l}\text { Filho et al. } \\
(2015)\end{array}$ & $\begin{array}{l}\text { Conclui que "[...] o usuário jogador }[. . .] \text { testará seus conhecimentos sobre o conteúdo } \\
\text { abordado, podendo aprender com as explicações da narrativa ou realizar pesquisas para } \\
\text { compreender qual a resposta correta para uma determinada pergunta. Quanto ao envolvimento } \\
\text { do jogador dentro da história do caso, podemos dizer [...] que uma criança consegue aprender } \\
\text { mais rapidamente vivenciando o objeto estudado." }\end{array}$ \\
\hline $\begin{array}{l}\text { Andrade e } \\
\text { Alves (2011) }\end{array}$ & $\begin{array}{l}\text { Ao relatarem a construção do jogo "Lukas James e os viajantes da história" afirmam que a: } \\
\text { "[...] proposta da narrativa nasceu, primeiramente, na constituição de uma ideia que mesclasse } \\
\text { elementos de realismo fantástico característicos de um jogo de RPG ao mesmo tempo em que } \\
\text { apresentasse uma história atrativa para o público proposto [...] (Andrade \& Alves, 2011, p. } \\
\text { 3)" }\end{array}$ \\
\hline
\end{tabular}

\subsection{Personagens}

Segundo Smith citado por Novak (2010), o games “[...] são um meio de narração visual. Neles, é comum que [...] o jogador atribua vários significados pessoais ao avatar ${ }^{12}[\ldots]$, e desperta no jogador sentimentos sobre [...] sua própria natureza."

Assim, na criação de um personagem, é preciso considerar que o jogador identifica-se com este Andrade e Alves (2011), Novak (2010); e definir: (a) o controle - se controlado pelo jogador, também denominado avatar, ou controlado pelo jogo; (b) origem - se animal, fictício, históricos, licenciado, ou mítico; (c) perfil - se arquétipo de personagens clássicos como o protagonista ou mentor, raça, classe econômica, habilidades; (d) evolução no jogo - de interesse intrapessoal a interesse pela humanidade; (e) pontos de vista - de primeira pessoa - jogador tem do jogo a perspectiva visual de um avatar; ou de terceira pessoa - o usuário do jogo pode ver o avatar na tela; (f) comportamento verbal - narração, monólogo ou diálogo; e o (g) 
movimento - o de assinatura, que demonstra o perfil do personagem, o ocioso que revela a espera de ação, e o de ação básica, a caminhada.

No Quadro 5 são apresentadas pesquisas que comungam da ideia de compor jogos digitais com personagens.

Quadro 5: Composição de Jogos Digitais com Personagens

\begin{tabular}{|c|c|}
\hline Pesquisas & Composição de Jogos Digitais com Personagens \\
\hline $\begin{array}{l}\text { Lopes et al. } \\
(2012)\end{array}$ & $\begin{array}{l}\text { Relatam que o InspSoft "[...] é um jogo educacional }[\ldots] \text { que proporciona um ambiente } \\
\text { lúdico possibilitando a escolha de um avatar para o jogador, um personagem para cada } \\
\text { objetivo de aprendizagem [...]". }\end{array}$ \\
\hline $\begin{array}{l}\text { Andrade } \\
\text { Alves }(2011)\end{array}$ & $\begin{array}{l}\text { Afirmam que "[...] assim como em um roteiro cinematográfico, podemos representar o } \\
\text { conflito do game através das ações do personagem [...] (Andrade \& Alves, 2011, p. 3)". }\end{array}$ \\
\hline $\begin{array}{l}\text { Matsunaga } \\
\text { al. }(2015)\end{array}$ & $\begin{array}{l}\text { No jogo voltado para crianças com hemofilia, alertam da existência de um tutor que é } \\
\text { desafiado a ensinar o conteúdo ao tutorado, e assim deverá aprender ainda mais ensinando o } \\
\text { próximo, e terá seus conhecimentos mais sedimentados. "No Hemotion, de forma análoga, a } \\
\text { criança com hemofilia representará o tutor do personagem do jogo, "ensinando" as condutas } \\
\text { mais adequadas nas diferentes situações-problema que serão apresentadas" (Matsunaga, } \\
\text { Borges e Maraes, } 2015 \text {, p. 55). }\end{array}$ \\
\hline Novak (2010) & $\begin{array}{l}\text { Smith citado por Novak (2010) acredita que: “[...] os aspectos mais poderosos da história se } \\
\text { desenrolam-na cabeça do jogador, não na tela. Games são um meio de narração visual. } \\
\text { Neles é comum que os melhores elementos da história sejam o cenário e o arquétipo do } \\
\text { personagem, por causa do processo que ocorre entre o jogador e o avatar [...] o jogador } \\
\text { atribui vários significados pessoais ao avatar e a natureza do avatar desperta no jogador } \\
\text { sentimentos sobre como idealiza sua própria natureza". }\end{array}$ \\
\hline
\end{tabular}

Personagens integrados ao roteiro, ao cenário e ao gameplay, devem instigarem nos utilizadores o desejo de continuar jogando. Assim como nas estórias infantis, no jogo eletrônico é preciso haver sinergia entre o roteiro os personagens principais, seus conflitos e obstáculos de forma a manter o jogador engajado.

Mas por outro lado, vale destacar que há jogos sem personagens como os de quebra-cabeça; os quais não deixam de cumprir a função de divertir seus jogadores.

\subsection{Jogabilidade}

Neste trabalho, entende-se que a jogabilidade, ou gameplay, correspondem às tarefas, às opções, aos desafios e às consequências que confrontam os jogadores durante o jogo. Para definição desta em um jogo, é preciso delinear:

- regras do jogo - determinam as possíveis ações, bem como as ações não permitidas; e também devem conter as condições de vitória e as condições de derrota;

- modos de interatividade - (a) jogador-game - representação espacial, exibição de informações, acesso a recursos que possibilitem ao jogador agir; (b) jogador-jogador comunicação entre jogadores e possibilidade de ações exercidas por um jogador sobre seus pares; (c) jogador-desenvolvedor - úteis, por exemplo, à coleta de subsídios para possíveis melhorias e/ou ajustes nos jogos; e (d) jogador-plataforma - incluem recursos gráficos e de áudio, performance dos dispositivos de controle, de armazenamento de dados e de autonomia de funcionamento;

- desafios - relacionam-se ao seu gênero, ao seu público alvo e à sua finalidade; segundo Novak (2010), na composição destes há: (a) desafios implícitos e explícitos - os explícitos são componentes do próprio jogo e os implícitos referem-se às estratégias de livre escolha do jogador; (b) informações perfeitas e imperfeitas - com as perfeitas os jogadores 
conhecem as condições reais do jogo e com as imperfeitas, precisam efetuar deduções sobre informações parciais; (c) conhecimentos intrínsecos e extrínsecos - o intrínseco é obtido no contexto do jogo e o extrínseco é proveniente do mundo real; (d) reconhecimento e associação de padrões - muito usado em jogos de quebra-cabeça por exemplo; (e) percepção espacial - requer que os jogadores se orientem nos ambientes de jogo; $(f)$ microgestão - com muitas opções de decisão e de configuração; $(g)$ tempo de reação - referente ao tempo de resposta do jogador; (h) metas - de progresso, de competição, de solução de enigmas, de exploração, de conflito, de captura, de perseguição, de organização, de evasão e de construção;

- equilíbrio - segundo Novak (2010), em “[...] um sistema equilibrado para os jogadores, a jogabilidade deve fornecer: [...] desafios gradualmente mais difíceis [...] experiências de jogo percebidas como justas [...] ausência de estagnação: os jogadores nunca podem ficar imobilizados e sem rumo [...] ausência de decisões banais [...] e os jogadores devem poder escolher um nível de dificuldade."

No Quadro 6 são ressaltados aspectos que revelam como a jogabilidade é trabalhada em pesquisas voltadas para composição de jogos digitais.

Quadro 6: Composição de Jogos Digitais com Jogabilidade.

\begin{tabular}{|l|l|l|}
\hline \multicolumn{1}{|c|}{ Pesquisas } & \multicolumn{1}{c|}{ Composição de Jogos Digitais com Jogabilidade } \\
\hline $\begin{array}{l}\text { Mota } \\
\text { Alencar } \\
(2015)\end{array}$ & e & $\begin{array}{l}\text { Quanto à jogabilidade, no EDUCPLAY o professor é o responsável em escolher e configurar } \\
\text { duas atividades: de caça vogais e de descobrir nomes, apropriadas ao processo de letramento. } \\
\text { "[...] os desafios possuem conteúdos ministrados em sala de aula, mas com o diferencial de } \\
\text { serem divertidas [...]" (Mota \& Alencar, 2015, p. 72) com score, cores, contagem de tempo } \\
\text { de resposta, feedback imediato. }\end{array}$ \\
\hline $\begin{array}{l}\text { Gularte } \\
\text { Alves (2011) }\end{array}$ & $\begin{array}{l}\text { Concluem que "Um aspecto importante dos jogos eletrônicos é então a jogabilidade. Este } \\
\text { critério trata do nível qualitativo de interação do jogo com as ações do jogador". (Gularte \& } \\
\text { Alves, 2011,p. 4) }\end{array}$ \\
\hline $\begin{array}{l}\text { Fadel et al. } \\
(2014)\end{array}$ & $\begin{array}{l}\text { "Habilidade é o núcleo de maior jogabilidade. Um "game" que não requer nenhuma } \\
\text { habilidade se tornará eventualmente chato. Os jogadores gostam de sentir que eles } \\
\text { dominaram o jogo. Alguns jogadores adoram oportunidade, enquanto outros desprezam e } \\
\text { querem que tudo seja baseado fora de habilidade" (Fadel et al., 2014, p. 188) }\end{array}$ \\
\hline $\begin{array}{l}\text { Matsunaga } \\
\text { al. (2015) }\end{array}$ & $\begin{array}{l}\text { No Hemotion, voltado para crianças com hemofilia, devido principalmente ao design } \\
\text { participativo, o utilizador "[...] pode selecionar a sequência de tarefas [...] O sistema fala a } \\
\text { linguagem do usuário, com palavras, frases e conceitos familiares para o usuário, ao invés de } \\
\text { termos orientados ao sistema" (Matsunaga et al., 2015, p. 57) }\end{array}$ \\
\hline
\end{tabular}

Em jogos digitais educativos o conteúdo de ensino, bem como a diversão devem estar em perfeita sinergia e intrínsecas à jogabilidade. Assim se garante que haja aprendizado por meio da diversão. Diferente dos ditos jogos em que o utilizador encontra tediosos textos e questões para trabalhar o conteúdo e em que minijogos são ofertados recompensas. E com o agravante dos minigames não terem nenhum vínculo com o tema trabalhado.

\subsection{Níveis}

Os níveis podem ser usados para estruturar um jogo digital em subdivisões eficazes, organizar a progressão e aprimorar o modo de jogar.

Ao se projetar níveis, conforme Novak (2010), deve-se considerar: (a) meta - que delimita os objetivos de um nível; (b) duração - variável conforme as metas, o público-alvo, o grau de dificuldade destes e o modo de jogar: se monojogador, dois jogadores, multijogador, multijogador em rede, multijogador online; (c) disponibilidade - quantidade de níveis do jogo, de forma a garantir que todas as metas estabelecidas sejam contempladas; (d) relações - entre os níveis, estabelecidas pelo tema do jogo, o qual deve ser preservado em todo game; e (e) 
dificuldade - que deve ser ampliada progressivamente, conforme o avanço dos níveis, exigindo maior esforço por parte do jogador para cumprir tarefas, para superar desafios ou para efetuar descobertas.

Pesquisas que enfatizam os níveis na composição dos jogos digitais são apresentados no Quadro 7.

Quadro 7: Composição de Jogos Digitais com Jogabilidade

\begin{tabular}{|c|c|}
\hline Pesquisas & Composição de Jogos Digitais com Níveis \\
\hline $\begin{array}{l}\text { Lopes et al. } \\
(2012)\end{array}$ & $\begin{array}{l}\text { elatam: "O jogo possui três níveis de desafio. No primeiro nível o jogador classifica o nome } \\
\text { o papel dos participantes no processo de inspeção de acordo com a função para adquirir } \\
\text { onhecimento sobre os papéis de Autor, Moderador e Inspetor [...]" (Lopes, Marques \& Conte, } \\
012 \text {, p. 5). }\end{array}$ \\
\hline $\begin{array}{l}\text { Põtter e Schots } \\
(2012)\end{array}$ & $\begin{array}{l}\text { Afirmam que: "Visando permitir um aumento gradual na complexidade das tarefas, } \\
\text { obedecendo à teoria do esforço cognitivo, o jogo varia gradualmente o nível de dificuldade } \\
\text { [...]" (Põtter \& Schots, 2012, p. 4). }\end{array}$ \\
\hline $\begin{array}{l}\text { Fadel et al. } \\
(2014)\end{array}$ & $\begin{array}{l}\text { "Através de conteúdos organizados em níveis desafiantes, apoiado por ação de feedback } \\
\text { motivacional, e incentivando conclusões de tarefas repetitivas através da melhoria de } \\
\text { pontuação, a empresa oferece produtos capazes de proporcionar avanços ao processo de } \\
\text { aprendizagem em comparação com um conteúdo "bruto" ou mesmo transposto em mídia } \\
\text { tradicional como o texto, por exemplo" (Fadel et al., 2014, p. 205) }\end{array}$ \\
\hline $\begin{array}{l}\text { Pires et } \\
(2015)\end{array}$ & $\begin{array}{l}\text { Os níveis do jogo correspondem às classes que um profissional pode assumir como analista de } \\
\text { dados atuando em empresas, nesta ordem: Estagiário (ETG), Analista de Dados Júnior (ADJ), } \\
\text { Analista de Dados Pleno (ADP) e Analista de Dados Sênior (ADS). O objetivo do jogo é } \\
\text { vencer uma determinada quantidade de partidas suficiente para que o jogador possa se tornar } \\
\text { um ADS. }\end{array}$ \\
\hline
\end{tabular}

Por meio dos níveis, os jogadores podem ser expostos gradualmente a contextos e conteúdos de diferentes dificuldades estimulando o engajamento, a motivação e o aperfeiçoamento almejado, já que, além de desafiá-los, evidencia e desperta o sentimento de progresso nos participantes.

\subsection{Interface}

A interface de jogos digitais deve possibilitar aos jogadores cumprir suas escolhas e ações com facilidade; assim assumindo o controle dos personagens, avançando pelo ambiente virtual e tomando decisões durante o game.

Para tanto, todas as ações possíveis do jogador no jogo devem ser consideradas; bem como a acesso a informações. São exemplos de ações: locomoção, acesso e manuseio de objetos virtuais e configurações. E são informações: tempo de jogo restante, número de vidas, como jogar, funções de cada objeto do cenário, e outras.

Narrativa, personagens, jogabilidade e níveis devem estar refletidos na interface.

As características visuais desta devem conter: o entorno, a atmosfera, a época histórica, e a cultura que compõe a narrativa; bem como a origem, o perfil, o ponto de vista, o movimento e o comportamento verbal dos personagens; e ainda as regras, modos de interatividade e desafios da jogabilidade; e os níveis.

$\mathrm{Na}$ composição da interface, o áudio atua junto ao visual, através de vozes, músicas, alertas de exibição de caixa de diálogo ou mudança de nível, e efeitos sonoros como estopins de tiros e grunhido de animais.

No Quadro 8 são apresentadas pesquisas que tratam sobre interface na composição dos jogos digitais. 
Quadro 8: Composição de Jogos Digitais com Interface

\begin{tabular}{|l|l|}
\hline \multicolumn{1}{|c|}{ Pesquisas } & \multicolumn{1}{c|}{ Composição de Jogos Digitais com Níveis } \\
\hline $\begin{array}{l}\text { Neto e Alves } \\
(2010)\end{array}$ & $\begin{array}{l}\text { Afirmam que: “[...] a importância do design de interface não somente está no desenvolvimento } \\
\text { de um layout bonito e criativo, mas, principalmente, no planejamento das interações [...]” } \\
\text { (Nesto \& Alves, 2010, p. 8. }\end{array}$ \\
\hline $\begin{array}{l}\text { Merelles, et al. } \\
(2011)\end{array}$ & $\begin{array}{l}\text { Concluem: “A interface gráfica é um aspecto que deve ser bastante trabalhado nos jogos } \\
\text { virtuais. Tanto no caso do SimulES-W como no SimSE, grande parte dos alunos apontou que } \\
\text { questões de usabilidade, comunicabilidade e jogabilidade afetaram o seu desempenho e } \\
\text { motivação". (Meirelles, Peixoto \& Monsalve, 2011, p. 5) }\end{array}$ \\
\hline $\begin{array}{l}\text { Matsunaga } \\
\text { al. (2015) et }\end{array}$ & $\begin{array}{l}\text { No desenvolvimento do jogo os pesquisadores envolver as crianças com hemofilia na } \\
\text { construção da interface. Destacam: "Toda a interface do jogo foi desenvolvida levando-se em } \\
\text { consideração os desenhos e ideias da dinâmica Braindraw13" (Matsunaga et al., 2015, p. 58) }\end{array}$ \\
\hline
\end{tabular}

$\mathrm{Na}$ composição das interfaces de jogos educativos, os elementos visuais como imagens, símbolos, gráficos, diagramas, ícones, e pictogramas devem ser significantes, uma vez que provocam diferentes tipos de estímulo e engajamento, e auxiliam na interação e na experiência do jogo, podendo significar recompensas ou motivando o aluno a continuar jogando, bem como materializando a segmentação do conteúdo em etapas que facilitam o entendimento e também a atenção.

\subsection{Considerações}

Os jogos digitais educacionais diferem dos jogos digitais de propósito geral, pois não podem limitar-se à diversão; devem incorporar objetivos educacionais Savi et al. (2011), Lopes et al. (2012), Andrade e Alves (2011); e contemplar conceitos, e/ou habilidades, a serem trabalhados por meio dos elementos de composição dos games; de forma a favorecer a aprendizagem, e assim garantir o equilíbrio entre educação e diversão - objeto de estudo do presente trabalho.

Dado o exposto, e partindo do pressuposto de que nos jogos supracitados a diversão é garantida, ao longo desta seção são apresentadas observações voltadas para o potencial educativo desses.

Desafios e recompensas devem servir de apoio à aprendizagem Mendes (2011), Gularte \& Alves (2011). Johnson citado por Mendes (2011) considera que “... o sucesso dos jogos digitais voltados para o entretenimento se dá [...] pelo seu potencial baseado na ideia de desafiorecompensa". O desafio de um jogo computacional pode ser para explorar simplesmente uma destreza motora, mas também pode favorecer a aprendizagem, tudo vai depender do seu delineamento.

Também a imersão pode beneficiar a aprendizagem Mendes (2011), Audi (2011). Esta, segundo Murray como citado em Audi (2011), "[...] é a experiência prazerosa de ser transportado para um lugar simulado, fantasioso, com a sensação de estar envolvido por uma realidade estranha que se apodera do sistema sensorial. O jogo, desta forma, teria de fazer o jogador focar sua atenção [...]”. Com atenção focada, se focos adequados, a aprendizagem é favorecida.

Além de desafios, recompensas e imersão, a interação pode favorecer à aprendizagem Gularte \& Alves (2011), Souza-Concílio e Pachaco (2013). Conforme Lopez citado por Gularte \& Alves (2011) "por ser uma ação que envolve aprendizado e experiência, o jogo deve fornecer facilidades e opções múltiplas, recompensas, para que cada vez o jogador possa jogar e tenha sempre novas formas de interagir" (Gularte \& Alves, 2011, p. 5) seja com o jogo ou com seus pares. Desta forma o aprendizado é favorecido pela interação; por meio das aprendizagens

13 Braindraw é um tipo de dinâmica de prototipação participativa. Trata-se de uma "tempestade de ideias" gráfico [...] o usuário pode desenhar o que está em sua mente sem receber críticas.[5] 
colaborativa ou explorativa, por exemplo.

Outros elementos de interação que podem favorecer a aprendizagem são a narrativa e mecânica, conforme Gularte \& Alves (2011), inspiradas na Taxonomia de Bloom (Seção 3).

Essencial para a composição de jogos digitais educacionais é considerar também a colaboração social como componente da aprendizagem Paraskeva et al. (2010), SouzaConcílio e Pachaco (2013). Muitas teorias de aprendizagem contemporâneas consideram que a colaboração social, geradora do capital social ${ }^{14}$, é um dos mais importantes componentes da aprendizagem. Fadel et al. (2014) destacam "iniciativas que buscam cooperação, colaboração e o compartilhamento entre indivíduos para resolver problemas que afligem grandes centros urbanos".

Outra característica essencial para os jogos digitais educacionais é a motivação para o jogador jogar e aprender Savi et al. (2011), Põtter e Schots (2012), Meirelles, et al. (2011), Gularte \& Alves (2011), Alves e Battaiola (2011). Bases teóricas voltadas para a motivação, usadas no processo de desenvolvimento de jogos digitais educacionais são: a Teoria do Fluxo Souza-Concílio e Pachaco (2013), Alves e Battaiola (2011) e o Modelo ARCS Lopes et al. (2012), Gularte \& Alves (2011), Souza-Concílio e Pachaco (2013), ver Seção 3.

"Um atrativo, motivador, de uso de jogos como ferramenta de ensino é que estes, [...] mesmo quando os alunos apresentam desempenho insuficiente nestes, não os associam a falhas, [...]" (Souza-Concílio \& Pachaco, 2013, p.40).

E para Alves e Battaiola (2011), a principal causa para a desmotivação é a falta de proximidade entre conteúdos escolares e o cotidiano do aluno. Sendo assim, a aplicação de jogos na educação é elemento de motivação para o aprender, já que os jogos fazem parte do diaa-dia de um significativo número de pessoas, conforme o levantamento estatístico apresentado na Seção 1.

Dessa forma, observa-se que os jogos digitais educacionais não devem voltar-se exclusivamente para a educação, diversão e educação devem ser adequadamente tratados Pires et al. (2015), Filho et al. (2015), Meirelles et al. (2011), Moita et al. (2013). Conforme Mendes (2011), o designer deve fazer uso de recursos metodológicos de forma a promover a sintonia entre os objetivos pedagógicos e os elementos voltados para o caráter divertido do jogo; e citando Ausubel, considera que: "[...] uma metodologia para o desenvolvimento de games com enfoque na aprendizagem precisa necessariamente se voltar para... 'como a interface e as mecânicas do jogo vão se relacionar e trazer novos conceitos que possam ser ancorados na estrutura cognitiva do jogador [...]'"'. Ou seja, no processo de desenvolvimento de jogos digitais educacionais, havendo equilíbrio entre entretenimento e educação Filho et al. (2015), Mendes (2011), Gularte \& Alves (2011), Chandler (2012), o jogo não falha na motivação e na atração próprias de sua natureza divertida, bem como não subutiliza seu potencial educacional.

\section{Gêneros}

Correspondem a classificações identificadas a partir da combinação de tema, ambiente, apresentação em tela, perspectiva do jogador e estratégia de jogo.

"Se uma maior variedade de gêneros de jogo é para ser usada na

\footnotetext{
14 Entende-se por capital social o valor coletivo associado a uma rede social trabalhada através de fluxos de informações, normas de reciprocidade, ações coletivas e solidariedade. [16]
} 
aprendizagem, uma melhor orientação deve ser fornecida sobre como as estes diferente tipos de jogos podem apoiar a aprendizagem de formas diferente, em termos de detalhamento das tarefas e atividades oferecidas em diferentes tipos de jogos." (Conolly, Boyle, MacArthur, Hainey e Boyle, 2012, p. 668)

Sendo assim, é indispensável para o desenvolvedor de jogos conhecer a diversidade de tipos de jogos e a distinção entre estes em termos de competitividade, composição de interface, narrativa e personagens, bem como de jogabilidade, de forma a dispor tais elementos de forma a favorecer sinergicamente a aprendizagem e a diversão.

\subsection{Jogos de Propósito Geral}

Segundo Connoly et al. (2012) não há consenso na taxonomia de tipos de jogos. Herz citado por Connoly et al. (2012) distingue: jogos de ação, jogos de aventura, jogos de luta, jogos de quebra-cabeça, simulações, jogos de esporte e jogos de estratégia. Já Novak (2010), os gêneros dos jogos de propósito geral são:

- ação - exigem destreza visiomotora por parte dos jogadores; nestes o jogador deve, em geral, eliminar, subjugar ou aprisionar, em tempo restrito, os adversários, sejam jogadores ou não; evitando, simultaneamente, sua própria morte no jogo; apresentam como subgênero: de plataforma, de tiro; de corrida e de lutas;

- aventura - onde a narrativa assume papel indispensável, motivando o jogador a jogar e orientando o progresso do jogo; geralmente baseiam-se em turnos, havendo tempo para o jogador pensar antes de agir; e os jogadores devem explorar, orientar-se em labirintos e decifrar enigmas;

- cassino - correspondente a versões eletrônicas de jogos de azar, a exemplo de roleta e bingo;

- quebra-cabeça - nestes o jogador deve solucionar um problema, e a narrativa e o controle de personagens é geralmente inexistente;

- games de representação de papéis (RPGs) - os jogadores assumem papéis de guerreiros, ladrões, sacerdotes, entre outros; com distintas habilidades e poderes; e com objetivos comuns ou contrários; podendo agir em grupos ou isolados; nestes a narrativa exerce papel essencial, motivando e orientando o jogador no game;

- simulações - visam reproduzir, virtualmente, sistemas, máquinas e experiências do mundo real; podem ser: de veículos, processos, ou participativos;

- de estratégia - os jogadores devem administrar um conjunto limitado de recursos para atingir uma meta específica;

- games on-line multijogador massivos - de representação de papéis on-line, envolvendo múltiplos jogadores; com interação social e narrativa complexa.

Há ainda, os jogos adultos ${ }^{15}$, os de Second Life ${ }^{16}$ e os empresariais Gularte \& Alves (2011), Schawaber e Sutherland (2013).

Importante ainda destacar que, conforme o público-alvo, há preferências de gêneros distintos. Neste fato reside a importância de se conhecer os gêneros de jogos, apesar de ser 
perfeitamente possível criar novos tipos, sejam totalmente autênticos, ou a partir da combinação de gêneros pré-existentes; que pode resultar da aplicação, por exemplo, da teoria que pressupõe a:

"[...] necessidade de se estabelecer experiências curriculares que posicionem não-especialistas como agentes de mudanças, os quais através da aplicação bem sucedida de seus ferramentais conceituais, podem ter experiências envolvendo contextos de mudanças reais, tornando-se assim pessoas com êxito em experiências acadêmicas [...]". (Barab, Pettyjohn, Gresalfi, Volk e Solomou 2012, p 525)

Além do gênero, há outros critérios a serem considerados para seleção, ou construção de um jogo:

- Forma de Gerência do Tempo - determina se este é jogado por reflexo ou reflexão; são: (a) baseado em turnos, onde cada jogador dispõe de um turno ilimitado para jogar; (b) em tempo real, os jogos não têm turnos e requerem dos usuários reflexos físicos rápidos; (c) e de tempo limitado, cada jogador dispõe de um turno limitado para efetuar suas jogadas.

- Modos de Jogar - relacionados à quantidade de usuários de jogos; são: (a) monojogador; (d) dois jogadores (c) multijogador local, quando os jogadores compartilham o ambiente, o jogo e a máquina; (d) multijogador em rede local, onde jogadores compartilham o ambiente, o jogo e a rede; e (e) multijogador online - sem necessidade de compartilhamento de ambiente e com uso de redes de longa distância, jogados por milhares de jogadores, estimulam a formação de equipes.

- Plataformas - os games desenvolvidos para cada plataforma diferem em diversos aspectos; são plataformas para jogos: (a) fliperama, (b) console, (c) computador, (d) web, e (e) portáteis.

\subsection{Educacionais}

Jogos educativos são aqueles especificamente criados para ensinar enquanto distraem.

Os jogos educativos, assim como os de propósito geral, podem ser totalmente autênticos. Mas também podem ser compostos a partir de recursos de composição dos gêneros préexistentes:

- simulações - jogos educacionais implementados por meio de simulações Lopes et al. (2012), Põtter e Schots (2012) e Novak (2010); há duas principais maneiras de se usar simulações em educação: (a) usando modelos, a exemplo dos jogos de treinamento empresarial em que os contextos de jogo simulam situações reais e requisitam soluções, e assim treinam e engajam pessoas e (b) construindo modelos, como jogos para ensino de programação em que os jogadores são estimulados a simularem animações a partir de blocos de instruções;

- colaboração social - jogos que exploram a cooperação entre os envolvidos Matsunaga et al. (2015), Paraskeva et al. (2010), como elemento de socialização de saberes e promoção de aprendizagem;

- aventura - games educativos construídos a partir da exploração de narrativas Filho et al. (2015), Andrade e Alves (2011), Novak (2010), Audi (2011); nestes, em geral, o jogador é o principal personagem na história e dirige-a avançando, interagindo com outros personagens e com o ambiente, e resolvendo desafios; o que, por sua vez, implica em ritmo, reflexão, observação do contexto, e resolução de problemas tornando este tipo de 
game relevante para práticas educacionais;

- de estratégia - games educacionais onde a tomada de decisões é indispensável para a formação autônoma, crítica e criativa; instigam decisões por parte do utilizador, com o mínimo de influência do fato sorte, logo dando lugar à estratégia; e em geral usam contextos histórica, política e econômicos, e são muito usados em treinamento militar e empresarial;

- second life - a pesquisadora e autora Jeannie Novak na Universidade do Sul da Califórnia usa o Second Life como sistema de aprendizado de cursos: "Seu objetivo é fazer os alunos ingressarem no ambiente virtual do Second Life e serem [...] os novos funcionários de uma empresa fictícia. Durante o curso [...] os alunos (personagens controlados pelos jogadores) conhecerão o funcionamento interno da empresa [...]" (Novak, 2010, p. 88). Assim, promove o aprendizado;

- de representação de papéis (RPG) - a socialização, a cooperação, a criatividade, a interatividade e a interdisciplinaridade que caracterizam os jogos de RPG os tornam excelente ferramenta educacional, pois a aprendizagem é favorecida pela imersão, engajamento e motivação dos jogadores.

Observa-se, assim, que cada gênero de jogo apresenta características distintas, compostos por elementos que devem ser modelados de acordo com o objetivo educacional almejado, em sinergia com entretenimento adequado ao objetivo almejado.

\subsection{Considerações}

Para treinamento militar, muitos jogos são criados para estudo de situações de combate. Para atender a este objetivo, o gênero de jogo mais adequado é de estratégia, a tomada de decisão tem excelente sintonia com o alvo educacional almejado; já os recursos voltados para o entretenimento, considerando a situação problema, não precisam ser tão elaborados. A eficácia do jogo é garantida mais pelo educar do que pelo divertir.

Já as simulações fornecem aos jogadores a oportunidade de experimentar ambientes inacessíveis, a exemplo de região em chamas, de visitar virtualmente lugares incomuns para experimentar conceitos científicos, e sensações e assim, conduzir experimentos. Esses podem ser ilustrados por: visita a planeta remoto, viagem ao fundo do mar, experiência química envolvendo produtos inflamáveis. Nestes casos os modelos e construções de modelos conduzirão o alcance do objetivo educacional, mas os recursos de entretenimento são indispensáveis para motivar e engajar o aluno. O ideal ocorre quanto elementos de composição dos modelos servem para ambas as funções: educar e divertir.

A seleção do gênero também pode ter efeito desastroso sobre o potencial de educação e diversão de um jogo. Considerando, por exemplo, um game com o objetivo de apresentar o alfabeto a pré-escolares. A construção desse por meio de estratégia - com tomada de decisão provavelmente o tornaria inadequado ao seu público alvo. Esta inadequação também resultaria em frustração e falta de diversão. Assim percebe-se que o gênero do jogo deve ser bem direcionado para contribuir com a adequada sinergia entre educar e divertir.

Quanto à gerência do tempo, as formas baseadas em turnos e de tempo limitado são as que melhor se adequam aos jogos digitais educativos; pois estimulam a reflexão e respeitam o ritmo de aprendizagem do aprendiz que são imprescindíveis em ambiente educacional. Já as formas em tempo real e de tempo limitada são mais compatíveis com ambientes competitivos de entretenimento.

Em relação aos modos de jogar, no contexto educacional, os jogos que contam com mais 
de um jogador, possibilitam negociações e intercâmbios contínuos entre pessoas com diferentes estilos cognitivos e emocionais o que favorece a aprendizagem, Souza-Concílio e Pachaco (2013), bem como a diversão.

Já para identificar a plataforma que se adequa à iniciativa de uso ou criação de jogos educacional, é indispensável analisar a compatibilidade das características da plataforma com os objetivos almejados. E é indispensável considerar a diversidade neste sentido: tecnologias mobile, jogos online, mundos virtuais, sistemas ubíquos; e outros.

\section{Motivação dos Jogadores}

Segundo Saunders citado por Novak (2010), “[...] O estudo das [...] motivações dos jogadores é um passo adiante rumo à questão[...]: o que torna um game divertido para um determinado tipo

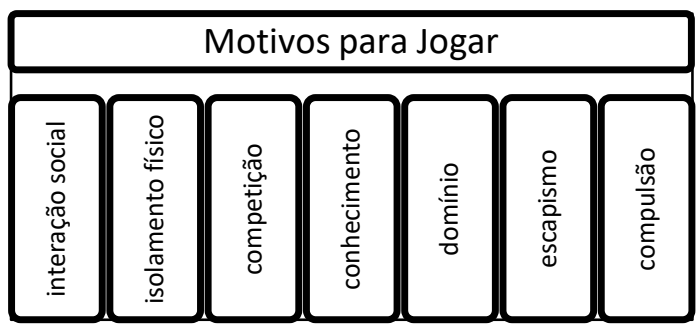

de pessoa?" (Novak, 2010, p. 98).

A Figura 1 ilustra fatores identificados como motivadores para os usuários jogarem no contexto de desenvolvimento de games de propósito geral.

Figura 1: Fatores que Motivam Usuários a Jogar

Baseado em Novak (2010)

\subsection{Considerações}

A função da 'motivação para jogar' e do entretenimento se confunde, logo, nesta seção, visando manter o equilíbrio alvo deste trabalho, o foco será lançado sobre a educação.

O fato de haver jogadores motivados, exceto pela compulsão, reforça a aplicação, no processo de construção de jogos digitais educativos, da Teoria do Fluxo Souza-Concílio e Pachaco (2013), Alves e Battaiola (2011) e do Modelo ARCS Lopes et al. (2012), Gularte \& Alves (2011), Souza-Concílio e Pachaco (2013), os quais partem do pressuposto de que a motivação é indispensável para que as pessoas aprendam.

A exceção da compulsão ocorre em virtude da incongruência de ocorrência de apelos viciantes em processos educativos; já que na educação é o desenvolvimento pleno que deve ser almejado e os vícios têm como consequência o fato de conduzir pessoas a ignorarem atividades importantes da vida.

Ainda, dentre as citadas motivações, destaca-se o conhecimento; pois no processo de criação de jogos educacionais o zelo com a aquisição de saberes deve permear cada decisão presente nesse. "Para criar um sistema de gamificação que incremente motivação para estudantes é necessário focar nos elementos fundamentais que fazem os videogames atraentes para seus jogadores". (Domínguez et al., 2013, p. 390)

A interação social pode ser favorecida pela aplicação da Teoria da Atividade Paraskeva et al. (2010) no desenvolvimento de games educativos. Esta pressupõe que a interação resulta em aprendizagem. 
Os jogadores motivados pelo isolamento físico têm a atenção, um dos pilares do Modelo ARCS Lopes et al. (2012), Gularte \& Alves (2011), Souza-Concílio e Pachaco (2013), reforçada, sugerindo a aplicação desta base teórica de aprendizagem na construção dos jogos digitais educacionais.

No processo de desenvolvimento de games voltados para a educação, quando estes forem direcionados a jogadores motivados pela competição, pode ser aplicada a Taxonomia de Malone e Lepper Souza-Concílio e Pachaco (2013), Alves e Battaiola (2011), já que esta sustenta-se no desafio, na fantasia (apelo emocional) e no controle, os quais são intrincados à predileção pelo competir.

Para atender aos jogadores motivados pelo domínio, duas teorias de aprendizagem se destacam: (a) o Construtivismo Gularte \& Alves (2011), Souza-Concílio e Pachaco (2013) - que pressupõe que a aprendizagem ocorre através da interação com o ambiente, o que é indispensável para que haja domínio; e (b) a Aprendizagem Autêntica - através da qual o jogo é composto por micromundo, Fadel et al. (2014), onde os jogadores são conduzidos a pensar, agir e resolver problemas como profissionais, o que implica na necessidade de domínio do contexto de trabalho.

E quando deseja-se alcançar os usuários de jogos digitais motivados pelo escapismo, os games educacionais devem garantir a ocorrência de imersão (Seção 4.6). Os jogos digitais correspondem a mundos virtuais, onde predomina a liberdade e a identidade, e através da imersão mensura-se o quanto se avançou nestes sentidos.

\section{Desenvolvimento de Jogos}

Devemos "[...] tornar nossos games mais divertidos e aumentar substancialmente a qualidade. Além disso, precisamos trabalhar com outros temas além de fantasia medieval ou ficção científica [...]" (Novak, 2010, p. 108).

Que dentre os supracitados outros temas, haja os educacionais, dispondo o fascínio que os jogos exercem sobre as pessoas, a serviço da sua formação pessoal, de forma divertida e eficiente. Porém, para tanto, é preciso compreender o processo de desenvolvimento de jogos digitais de propósito geral, para com estes aprender a construir jogos divertidos e, em sinergia, educativos.

Além do processo de desenvolvimento, para construção de jogos faz-se necessário aplicar ferramentas. Para desenvolvimento de jogos digitais há as Ferramentas de Autoria e as Ferramentas de Desenvolvimento de Jogos.

\subsection{Processos de Construção}

Novak (2010) propõe um processo de desenvolvimento composto por oito fases:

- conceito - inicia quando uma ideia de jogo é criada e termina quando é tomada a decisão de começar a planejar o projeto, nesta identifica-se o público-alvo e avaliam-se os recursos disponíveis; nesta são confeccionados: (1) o Documento de Conceito composto por: premissa, motivação do jogador, diferencial - o que torna o jogo único, público-alvo, gênero, classificação etária, plataforma de destino e requisitos de hardware, licença, análise competitiva, e objetivos; e (2) Proposta do Game, que deve conter: (a) gancho - elemento que atrairá os jogadores para o game; (b) modo de jogar; (c) recursos on-line; (d) tecnologia; (e) características da arte e do áudio; (f) detalhes da produção - equipe de desenvolvimento, orçamento e cronograma; (g) 
história anterior; (h) sinopse da história; (i) descrição dos personagens; (j) análise de riscos; (k) orçamento de desenvolvimento e (l) arte conceitual;

- pré-produção - quando são elaborados o Documento de Design do Game (GDD), o Documento Técnico do Design e Guia de Estilo da Arte; no GDD deve haver a descrição de: (a) interface do game; (b) habilidades e itens dos personagens; (c) modo do game; e (d) motor do game - número de personagens que podem estar presentes na tela simultaneamente, número de animações por personagem, e restrições ao ponto de vista da câmera e do game; com base no GDD é proposto o Documento Técnico de Design do Game, que descreve aspectos específicos do motor do game - o software em que o jogo se baseia; e o Guia de Estilo da Arte que consiste em um conjunto de ilustrações, e estabelece a aparência geral do game;

- protótipo - item de software através do qual pode ser testado se o game é divertido e atraente; independente do estilo visual deste;

- produção - quando o protótipo é testado;

- alfa - corresponde ao ponto em que o game pode ser jogado do começo ao fim; com motor e interface do usuário completos. Nesta, cada módulo do game deve ser testado e deve ser feito um banco de dados de defeitos, a bugbase e o Plano de Testes que contém hipóteses a serem testadas, lista de verificação discriminando cada aspecto ou área que deve ser enfocada durante o processo de testes.

- beta - esta volta-se principalmente para o desenvolvimento final do código, conteúdo, texto em diferentes idiomas, navegação pelo percurso do game, interface do usuário, compatibilidade de hardware e de software, e da interface manual, arte e áudio, e manual;

- ouro - quando o software é disponibilizado aos usuários finais;

- pós-produção - quando são lançadas versões pós-lançamento: (a) de correções - de falhas; (b) de atualizações - de aprimoramento do jogo original; e (c) de expansão - com preservação do tema do jogo, mas ampliações de metas.

Quadro 9: Processos de Desenvolvimento

\begin{tabular}{|c|c|}
\hline Novak (2010) & \multirow{2}{*}{ Chandler (2012) } \\
\cline { 1 - 1 } Ponceito & \multirow{2}{*}{ Pró-Produção } \\
\hline Pré-Produçao & \multirow{2}{*}{ Produção } \\
\hline Produção & Testes \\
\hline Alfa & \\
\hline Beta & Pós-Produção \\
\hline Ouro & \\
\hline Pós-Produção &
\end{tabular}

Há ainda processo de desenvolvimento, proposto por Chandler (2012), mais recente, onde são identificadas quatro principais fases: (1) Pré-Produção, (2) Produção, (3) Testes e (4) PósProdução; mas correspondentes às etapas propostas por Novak (2010) conforme Quadro 9.

Nestes, as metodologias de desenvolvimento de software, a exemplo do Scrum, são aplicadas na fase de Produção, e implicam em benefícios como permitir que a equipe veja claramente o progresso alcançado, motivando-a, e por meio do uso de gráficos permitem aos desenvolvedores ver se estão adiantadas, atrasadas ou conforme cronograma, ajustando o ritmo quando necessário.

O Scrum corresponde a um framework cuja aplicação, segundo Sutherland (2014) implica na criação de uma lista de tudo que é preciso fazer no projeto - pendências - e ordenação desta de for-ma a priorizar os itens de maior valor e menor risco; definição de caixas de tempo - 
sprint - para execução de blocos de pendências; organização de equipe de execução que se reune diariamente por 15 minutos para troca de ideias e avaliação do andamento da sprint; eleição de uma pessoa - o dono do produto - que define o que precisa ser feito e por quê e outra pessoa pessoa - o líder - que propõe a forma de fazer; elaboração de relação do que foi feito e de gráfico burndown que mostra o progresso em direção ao objetivo, além de retrospectiva e velocidade para medir o quanto foi feito em relação ao tempo, e as-sim obter agilidade superior

\begin{tabular}{|c|c|c|c|c|}
\hline Phase & Activity & Deliverables & Week & Lecture Topics \\
\hline & Start & & 1 & Organizational Matters \\
\hline \multirow{4}{*}{$\begin{array}{l}\overrightarrow{0} \\
\frac{0}{00} \\
0 \\
0\end{array}$} & Idea Creation & \multirow{4}{*}{$\begin{array}{l}\text { Game Design Document, Product Backlog, } \\
\text { Alpha Sprint Backlog }\end{array}$} & 2 & Genres, Innovation and Ideas \\
\hline & Grouping & & 3 & Production Process \\
\hline & Conception & & 4 & Production Tools \\
\hline & Planning & & 5 & Project Engineering \\
\hline \multirow{11}{*}{ 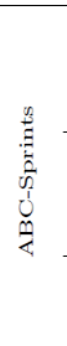 } & \multirow{4}{*}{ Alpha Sprint } & \multirow{4}{*}{$\begin{array}{l}\text { Basic Functionality, Proof of Concept, } \\
\text { Beta Sprint Backlog }\end{array}$} & 6 & Structure of Games \\
\hline & & & 7 & Gameplay and Balancing \\
\hline & & & 8 & Interface Design \\
\hline & & & 9 & M1 ALPHA VERSION \\
\hline & \multirow{4}{*}{ Beta Sprint } & \multirow{4}{*}{$\begin{array}{l}\text { Feature-complete Game, Final Assets, } \\
\text { Completion Sprint Backlog }\end{array}$} & 10 & Christmas Gaming Session \\
\hline & & & 11 & Interactive Storytelling \\
\hline & & & 12 & Character Development \\
\hline & & & 13 & M2 BETA VERSION \\
\hline & \multirow{3}{*}{ Completion Sprint } & \multirow{3}{*}{ Bug-free, Balanced, Polished, and Finalized Game } & 13 & Code Review and Refactoring \\
\hline & & & 14 & Games Business \\
\hline & & & 15 & M3 RELEASE \\
\hline
\end{tabular}

aos outros métodos de construção de produtos.

Entretanto, segundo relata Chandler (2012), existem "algumas desvantagens no uso de um proces-so formal de engenharia de software [...] Um problema do uso de processos como o Scrum [...] no desenvolvimento de jogos é que esses processos são mais adequados para tarefas de engenharia e menos para tarefas de design e artísticas" (Chandler, 2012, p. 88).

Parson, L. citado por Chandler (2012) relata que:

"[...] a união entre o Scrum e o desenvolvimento de jogos não funciona de maneira ideal é a na organização de equipes. Uma ideia [...] do Scrum é a de que esforços colaborativos geram resultados melhores, e assim criamos equipes com menos pessoas para trabalhar juntas no mesmo recurso. Mas há algumas tarefas altamente especializadas [...] onde o esforço colaborativo não é realmente necessário. [...] a natureza interdisciplinar de um grupo é menos importante quando [...] as pessoas estão trabalhando em assets reais do jogo" (Chandler, 2012, p. 98).

Por outro lado, Schild, Walter e Msuch (2010) propõem método de construção de jogos digitais baseado no Scrum, o "ABC-Sprints", delineado para composição de curso de desenvolvimento de games.

O "ABC-Sprints" é composto por três sprints para criar de forma iterativa, versão Alpha, Beta e Completas de um jogo. Neste os autores julgam como competências indispensáveis ao desenvolvimento de um jogo: comunicação entre os membros da equipe, habilidades para acompanhar os processos, para cumprir objetivos, e transformar requisitos e feedback em metas factíveis; e propõem a aplicação de método de desenvolvimento ágil por meio de quatro fases: Design, Sprint Alpha, Sprint Beta e Sprint de Conclusão.

Seguindo o ciclo de vida de um jogo, a fase de Design corresponde à Pré-Produção (Seção 7.1) e as outras supracitadas etapas - sprints - à Produção.

O objetivo da fase de Design é conduzido por sessões de brainstorm estimulando a criação da concepção do projeto: gênero, ferramentas e objetivos. Na Alpha Sprint, ao final das quatro semanas, deve ter sido desenvolvido um primeiro protótipo em que a funcionalidade básica do jogo é implementada. Na Beta Sprint devem ser adicionados níveis, inimigos e táticas tornando 
o jogo um recurso completo. As duas semanas da Conclusão Sprint é para depuração. Ver Figura 2.

\author{
Figura 2: Método ABC-Sprints
}

(Barbosa, Pereira \& Dias, 2014, p. 89)

Sendo assim, observa-se, a partir da análise do "ABC Sprint” que é possível a aplicação de processos de desenvolvimento de software no desen-volvimento de jogos; mas devem ser adaptados, de forma a contemplar a construção dos recursos de design e artísticos, conforme sinaliza Chandler (2012) - narrativa, personagem, roteiro, jogabilidade, interface, arte, níveis (Seção 4). E quando se trata de jogos digitais voltados para a educação ainda é indispensável promover o ensino, incorporar os conhecimentos aos elementos de jogo, buscando promover sinergia entre o divertir e o educar.

\title{
7.2 Processo de Desenvolvimento de Jogos Digitais Educacionais
}

O desenvolvimento de jogos digitais educacio-nais requer metodologia específica; "deve utilizar um formato metodológico que possibilite produzir a melhor relação entre objetivos pedagógicos, sistema de desafios e recompensas e a narrativa do jogo para que o processo de aprendizagem seja divertido e eficiente [...]" (Mendes, 2011, p. 04).

Entretanto, em trabalho de Revisão Sistemáti-ca de Literatura acerca dos processos de desen-volvimento de software utilizados no desenvolvi-mento de jogos eletrônicos educacionais, Neto, Reinehr e Malucelli (2015) concluem “[...] nenhum dos artigos analisados discute fortemente a questão educacional, principalmente, as abordagens das habilidades cognitivas e psicomotoras em seu contexto, mes-mo sendo jogos eletrônicos voltados ao âmbito da educação [...]" sinalizando que ainda há lacunas neste sentido.

No presente trabalho, para identificação de processos de desenvolvimento de jogos digitais educacionais, foi efetuada busca por artigos, nas bases científicas: Scopus, Springer e Science Di-rect; por meio da string de busca: ((digital game development) OR (game development life cycle) OR (game development methodology)) AND (edu-cational OR education OR training) $A N D$ (diver-sion OR fun OR entertainment), tendo como retor-no um total de 298 artigos, reduzidos a 39 ao se estabelecer o intervalo de tempo entre 2010 e 2016; dos quais apenas dois detalham o método de construção de game digital educativo: (1) Wendel, Gutjahr e Steinmetz (2013) e (2) Barbosa, Pereira e Dias (2014)

Wendel et al. (2013) corroboram com a ideia de que as metodologias de cons-trução de jogos abordam tópicos como metas, imersão, gráficos, som e tecnologias de rede. No entanto, no campo dos jogos sérios há desafios adicionais, já que os jogos para aprendizagem, além de atender aos mesmos requisitos, devem equipar o utilizador com o conhecimento.

Os supracitados autores, para complementarem o processo de construção de jogos, identificam requisitos indispensáveis aos recursos tecnológicos educativos e de colaboração, a exemplo de: comunicação, tarefas colaborativas, e heterogeneidade de recursos.

Dado o exposto, buscam garantir que os jogadores sejam capazes de se comunicarem uns com os outros através de sistema integrado de bate-papo; procuram estimular a colaboração pela proposição de tarefas solucionáveis apenas se os utilizadores agirem em grupo e distribuem ferramentas diversificadas entre os alunos: mapas, emblema de caçador, apito, de forma a possibilitar que cada um desempenhe uma tarefa exclusiva no jogo.

Dessa forma observa-se que a metodologia de construção de jogos precisou ser complementada por estratégias exportadas do processo de construção de objeto de aprendizagem colaborativo, para cunhar o adjetivo 'educativo' no produto final. 
O aprendizado "deve ocorrer dentro de vários mecanismos, tais como mini-jogos, puzzles e quizzes, jogado em paralelo ao ambiente do jogo principal, mas também pela jogabilidade, por meio da resolução de missões no jogo" (Barbosa et al., 2014, p. 88).

O game, segundo a metodologia de desenvolvimento de jogos educativos, proposta por Barbosa et al. (2014) é dividido em níveis, os quais são compostos por múltiplos mecanismos de aprendizagem, e nos quais o jogador tem missões a cumprir, como forma de acessar o aprendizado, ver Figura 3.

Figura 3: Fluxograma de Composição de Nível em Jogo Exemplo

(Barbosa et al., 2014, p.90)

$\mathrm{Na}$ Figura 3 identifica-se, representado por seta horizontal central, o primeiro nível de um jogo. Em paralelo, representado por retângulos delimitado apenas por bordas, há a definição e o sequenciamento do conteúdo educational e evntos; e em retângulos com preenchimento o posicionamento e o tema de mini-jogos.

Assim observa-se que a metodologia é composta por dois elementos principais: (1) um jogo principal, com missões e (2) um conjunto de, então denominados pelos proponentes, mecanismos de aprendizagem: mini-jogos, puzzles e quizzes. Logo, concluem os autores: "o conhecimento é incorporado principalmente nos mecanismos que aparecem durante o jogo, o que significa que o jogo principal pode ser mais orientado para o fator diversão de forma a envolver mais o jogador".

A possibilidade de visualização clara da rela-ção entre o game e conteúdo educacional é um aspecto positivo desta metodologia. Através do fluxograma apresentado na Figura 3 também se subentende a necessidade de organização prévia dos conhecimentos a serem explorados no jogo, e catalogado em níveis de jogo.

Entretanto a ideia de conferir a diversão ao jo-go principal e o ensino aos mecanismos de

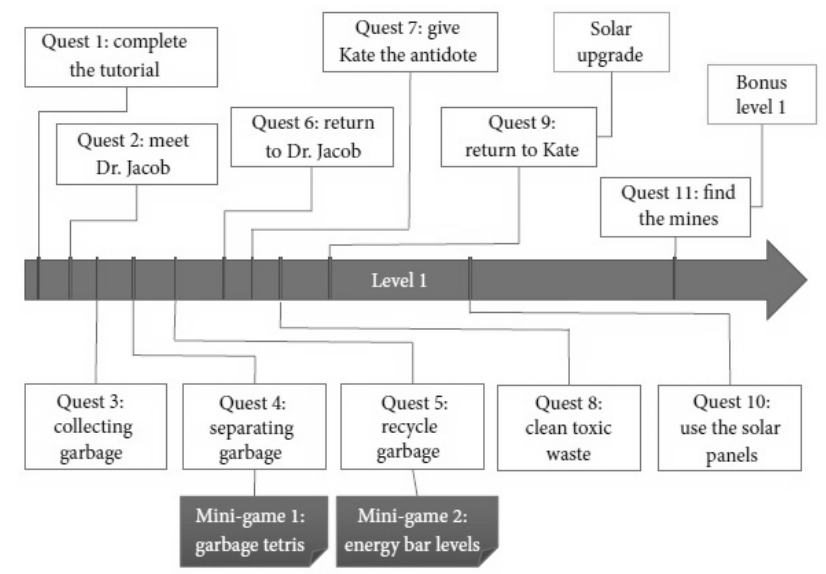

apren-dizagem, estimula uma dicotomia entre o divertir e o educar que não é condizente com a ideia de aprender enquanto se diverte. O ideal seria que o conteúdo estivesse sinergicamente embebido nos elementos do jogo; que o conhecimento fosse trabalhado intrinsecamente por meio dos persona-gens, narrativa, jogabilidade.

\subsection{Considerações}

Para seleção de modelos para construção de games, são critérios válidos: atendimento aos re-quisitos do jogo, compatibilidade entre ferramen-tas e plataformas de hardware e software a 
serem usadas, acessibilidade em relação a custos, quali-dade dos produtos obtidos a partir da aplicação dos recursos selecionados; facilidade de aprendi-zado e uso destas.

O processo de desenvolvimento proposto por Novak (2010) compatível com o ciclo mais recen-temente delineado por Chandler (2012) (Seção 7.1) apresenta um sequenciamento de ações, bem como documentos, que direcionam e descrevem a construção de jogos. Estes são importantes para o desenvolvedor porque correspondem a uma siste-mática que facilita a execução do trabalho por conter uma sequência lógica a seguir; e facilitar a construção em equipe, o planejamento e a docu-mentação, preservando a coesão das atividades.

Porém, os modelos de construção de software, a exemplo do Scrum, ainda precisam se adaptar para que haja um alinhamento com o ciclo de vida do jogo, pois é preciso definir o momento de construção dos elementos de design e arte próprios de jogos, bem como a coesão e clareza destes.

Já quando é almejada a construção de jogos digitais educativos, os modelos de construção de software precisam ainda incorporar, além de nar-rativa, personagem, roteiro, jogabilidade, interface, níveis (Seção 4), também os conteúdos de apren-dizagem.

Corroboram com essa ideia: "Para jogos educacionais, designers devem também considerar a conexão entre a jogabilidade e a aprendizagem". (Haworth \& Sedig, 2011, p. 520)

Para tanto, pode-se adicionar ao processo de desenvolvimento de games, orientações pertinen-tes à construção de objetos de aprendizagem co-mo foi efetuado por Wendel et al. (2013); desde que preservada a atenção às bases teóricas (Seção 3) que sustentam as citadas orien-tações, de forma a garantir que sejam adequadas com os objetivos de ensino almejados, pois, como dito "para se criar uma ferramenta educacional, deve-se escolher que modelo de educação é mais adequado para o problema proposto" (Gularte \& Alves, 2011, p. 8).

Também se faz necessário, no processo de desenvolvimento do game, buscar formas que garantam clareza na relação entre os elementos de jogo e os conteúdos educativos de forma que não seja possível dissociá-los, promovendo o aprender por meio da diversão. Neste sentido o trabalho de Barbosa et al. (2014) faz um bom ensaio, apesar de requerer ajustes para a obtenção da sinergia almejada.

Dado o exposto, apesar de observa-se avanços no sentido de obter-se um modelo que norteie o processo de construção de jogos educativos, faz-se preciso manter os esforços neste sentido de maneira a identificar-se orientações mais seguras com vistas à obtenção de jogos que educam sem perder a sua essência de divertir, e ainda mais, que não haja divisas entre a diversão e a aprendizagem, mas sim uma aprendizagem divertida, ou uma diversão que educa.

\section{Conclusão}

Jogos computacionais podem, de forma diver-tida e prazerosa, favorecer o ensino e a aprendizagem: desenvolvendo a atenção, a disciplina, a iniciativa, o autocontrole, o respeito a regras e habilidades perceptivas e motoras dos jogadores - indispensáveis no ato de jogar; estimulando o respeito mútuo, a solidariedade e a cooperação no cumprimento das tarefas em grupo; oportunizan-do, para o aluno, o uso da lógica, do raciocínio e de habilidades de organização para resolver pro-blemas e superar desafios; bem como reforçando a autoestima dos seus usuários ao possibilitar que estes tenham bom desempenho, sejam imediatos, ou conquistados gradualmente.

Para tanto faz-se necessário adotar embasa-mento teórico - Construcionismo, Teoria do Fluxo, Taxonomia de Bloom, Aprendizagem Significati-va, ou outro - que alicerce a motivação, 
o interes-se e a aprendizagem, os quais devem ser garanti-dos na construção e aplicação dos jogos sérios.

As formas de aplicação dos jogos na educação também são variadas. Há as que usam jogos educativos, bem como os jogos de entretenimento. Existe ainda proposta para se adaptar jogos de entretenimento, de forma a diminuir os curtos na construção dos games sérios de aprendizagem.

Narrativa, personagens, jogabilidade, níveis e interface são alguns dos componentes chaves dos jogos digitais; mas quando estes últimos são edu-cacionais, estes elementos de composição devem se adequar à função de educar: deve haver siner-gia entre diversão e educação, objetivos pedagógi-cos devem ser bem definidos e nortear o processo de construção.

Os gêneros dos jogos também são múltiplos: de aventura, de simulação, de RPG, de estratégia; podendo atender, conforme suas particularidades, aos objetivos da infinda diversidade de temas educacionais a serem abordados por meio de jo-gos.

O público alvo, as formas de gerência do tempo, o modo de jogar e as plataformas dos jogos educativos são outras variáveis a serem consideradas no processo de aplicação dos games na educação. Todas com diversas possibilidades de configuração e combinação. Pode-se, por exem-plo, adotar um jogo voltado para o público que visa escapismo, baseado em turnos, monojogador e para dispositivos portáteis; ou um game que estimule competição, de tempo limitado, multijo-gador on-line e para computador; tudo depende dos objetivos a serem alcançados e das condições de construção dos jogos.

As ferramentas de desenvolvimento de jogos que podem ser aplicadas também são inúmeras, envolvendo: ferramentas de autorias, linguagens de programação, bancos de dados, game engines, e outras; eleitas conforme o contexto de construção do game.

Quanto ao processo de construção, faz-se pre-ciso delinear uma metodologia composta por objetos e interfaces definidos e validados, com encadeamento das etapas de desenvolvimento e definição clara da interdependência destas, de forma a favorecer a boa aplicação de personagens, narrativa, jogabilidade, níveis, sintonizados à teoria de estímulo à aprendizagem bem como a aplicação de uma teoria motivacional, construindo uma ferramenta educacional, sem perder de vista a necessidade de garantir a diversão.

Assim, para promover sintonia ente a diversão e a educação, na criação de jogos digitais educa-cionais é preciso zelar pelo cumprimento deste objetivo ao se avançar nas inúmeras discussões presentes neste projeto: desde a forma de aplica-ção do jogo, passando por seu embasamento teórico, jogabilidade e níveis até o processo de desenvolvimento do mesmo. Em nenhum estágio de discussão a sinergia entre o entretenimento $\mathrm{e} o$ educar pode ser negligenciado.

E ao se falar em sinergia entre diversão e educação nos jogos, entenda-se que a diversão não deve ser nem somente a recompensa, nem somen-te a motivação; mas o meio através do qual se aprende.

Em trabalhos futuros é prociso avaliar mais detalhadamente a forma como cada elemento de composição dos jogos digitais educacionais contribuem para o processo desenvolvimento destes.

\section{Referências}

Alves M. M. \& Battaiola, A. L. (2011). Recomendações para ampliar motivação em jogos e animações educacionais. Anais do X Simpósio Brasileiro de Games e Entretenimento Digital - SBGames2011, (pp. 1-5), Salvador - BA, Brasil. 
http://www.sbgames.org/sbgames2011/proceedings/sbgames/papers/art/short/92008.pdf. [GS Search].

Andrade, G. E. \& Alves, L. (2011). Lukas James e os viajantes da história: influências cinematográficas na criação do roteiro para um jogo eletrônico. Anais do X Simpósio Brasileiro de Games e Entretenimento Digital - SBGames2011, (pp. 1-9), Salvador - BA, Brasil.

http://wwwsbgames.org/sbgames2011/proceedings/sbgames/papers/art/full/92362.pdf. [GS $\underline{\text { Search }}$

Araujo, T., Leal, J. \& Evangelista, A. (2014). A Utilização de Jogos Eletrônicos no Ensino da Geografia no Contexto da Tecnologia Educacional. Anais do VII Congresso Nacional dos Geógrafos. Vitória - $\quad$ ES, Brasil. http://www.cbg2014.agb.org.br/resources/anais/1/1404695115 ARQUIVO Autilizacaodei ogoseletronicosnoensinodageografianocontextodatecnologiaeducacional.pdf. [GS Search]

Audi, G. M. (2011). Cognição e Videogame: o jogo narrativo e o uso do corpo como interface. Anais do X Simpósio Brasileiro de Games e Entretenimento Digital - SBGames2011, (pp. 1-10), Salvador - BA, Brasil. http://www.sbgames.org/sbgames2011/proceedings/sbgames/papers/art/full/91324.pdf.

Barab, S., Pettyjohn, P., Gresalfi, M., Volk, C, \& Solomou, M. (2012). Game-based curriculum and transformational play: Designing to meaningfully positioning person, content, and context. Computers and Education. 58(1):518-533. doi: 10.1016/j.compedu.2011.08.001. [GS Search].

Barbosa B., Pereira, P. \& Dias J. (2014). A New Methodology of Design and Development of Serious Games. International Journal of Computer Games Technology, (8 p.). doi: 10.1155/2014/817167. [GS Search].

Cechin, V., Trois, S. \& Silva, T. (2012). Adaptação de jogos comerciais para a sala de aula. Anais do Simpósio Brasileiros de Games - SBGames 2012. (pp: 184-187), Brasília-DF, Brasil. http://sbgames.org/sbgames2012/proceedings/papers/cultura/C S15.pdf.

Chandler, H. (2012). Manual de Produção de Jogos Digitais. (2a. Edicção) Bookman, Porto Alegre-RS, Brasil. [GS Search]

Connolly, T. M., Boyle, E., MacArthur, E., Hainey, T. \& Boyle, J. M. (2012). A systematic literature review of empirical evidence on computer games and serious games. Computers \& Education, 59(2):661-686, Elsevier, Science Direct. doi: 10.1016/j.compedu.2012.03.004. [GS Search].

Domínguez, A., Saenz-De-Navarrete, J., De-Marcos, L., Fernández-Sanz J., Pagés, C. \& Martínez-Herráiz, J. (2013). Gamifying learning experiences: Practical implications and outcomes. Computers and Education, 63:380-392, Elsevier, ScienceDirect. doi: 10.1016/j.compedu.2012.12.020. [GS Search].

Fadel, F., Ulbricht, V. e Batista, C. (Organizadores). (2014). Gamificação na educação. Pimenta Cultural, São Paulo - SP, Brasil. [GS Search]

Filho, C., Costa, C. \& Dominguez, A. (2015). Um Jogo Digital Baseado no Construcionismo. Revista Brasileira de Informática na Educação, 23(2): 175-189. doi: 10.5753/RBIE.2015.23.02.175. [GS Search].

Gularte, D. M. \& Alves, F. A. F. (2011) Operação Risco: Desafios no Uso de Metodologias de Game Design para Jogos Educacionais nas Empresas. Anais do X Simpósio Brasileiro de 
Games e Entretenimento Digital - SBGames2011, (pp. 1-11), Salvador - BA, Brasil. http://www.sbgames.org/sbgames2011/proceedings/sbgames/papers/art/full/92030.pdf.

Haworth, R. \& Sedig, K. (2011) The importance of design for educational games. Education in a technological world, (pp. 518-522). http://www.formatex.info/ict/book/518-522.pdf. [GS Search].

Lopes, A. P. L. (2011) Lições em Jogo. Revista de História da Biblioteca Nacional. http://www.revistadehistoria.com.br/secao/educacao/licoes-em-jogo.

Lopes A. C., Marques A. B. \& Conte, T. (2012). Avaliação do Jogo InspSoft: Um Jogo para o Ensino de Inspeção de Software. Anais do V Fórum de Educação em Engenharia de Software - FEES 2012, (pp. 01-08), Natal - RN, Brasil. http://fees.inf.pucrio.br/FEESArtigos/artigos/artigos_FEES12/104376.pdf [GS Search]

Matsunaga R, Borges M. \& Moraes R. (2015). Desenvolvimento de um jogo educativo para crianças com hemofilia. Revista Brasileira de Informática na Educação. 23(2): 59-69. doi: 10.5753/rbie.2015.23.02.60. [GS Search].

Meirelles, L., Peixoto, D. \& Monsalve, E. (2011). Uso de Jogos para o Ensino de Engenharia de Software. Anais do IV Fórum de Educação em Engenharia de Software - FEES 2011, (pp. 01-08), São Paulo http://homepages.dcc.ufmg.br/ figueiredo/publications/fees11ready.pdf. [GS Search].

Mendes, T. G. (2011). Jogos Digitais como Objetos de Aprendizagem: Apontamentos para uma Metodologia de Desenvolvimento. In Anais do X Simpósio Brasileiro de Games e Entretenimento Digital - SBGames2011, (pp. 1-8), Salvador - BA, Brasil. Recuperado de: http://www.sbgames.org/sbgames2011/proceedings/sbgames/papers/art/full/92067.pdf. [GS Search].

Moita, F. M., Luciano, A. P. \& Costa, A. T. (2013). Angry Birds como contexto digital educativo para ensino e aprendizagem de conceitos matemáticos: relato de um projeto. Anais do XII Simpósio Brasileiro de Games e Entretenimento Digital - SBGames2013, (pp. 121-127), São Paulo http://www.sbgames.org/sbgames2013/proceedings/cultura/Culture-17 full.pdf. $\quad$ [GS Search].

Mota, R \& Alencar M. (2015). EDUCPLAY Jogo Educativo destinado ao Letramento no Ensino Infantil. Anais do Encontro Regional de Computação e Sistemas de Informação, (pp. 7178), Manaus - AM, Brasil. [GS Search].

Morais, R. e Mendes, D. (2013). O Esporte - Simulação: O Que É Possível Aprender Com Os Jogos Eletrônicos? Atos de Pesquisa em Educação. 8(1):209-238, Rio de Janeiro-RJ, Brasil. http://proxy.furb.br/ojs/index.php/atosdepesquisa/article/viewFile/3669/2303. [GS Search].

Neto, F. D. S. \& Alves, L. (2010). Jogos Digitais e Aprendizagem: Um Estudo de Caso sobre a Influência do Design de Interface. Anais do IX Simpósio Brasileiro de Games e Entretenimento Digital - SBGames2010, (pp; 1-10), Florianópolis - SC. http://www.sbgames.org/papers/sbgames10/artanddesign/Full_A\&D_15.pdf. [GS Search].

Neto, J. C., Reinehr, S. \& Malucelli A. (2015). Processo de Desenvolvimento para Jogos Eletrônicos Educacionais: uma Revisão de Literatura. Revista Brasileira de Informática na Educação, 23(2), (pp. 84-98). doi: 10.5753/rbie.2015.23.02.84. [GS Search].

Novak, J. (2010). Desenvolvimento de Games (Tradução da 2a Edição Norte-Americana). Cengage Learning, São Paulo - SP, Brasil. [GS Search] 
Paraskeva F., Mysirlaki, S. \& Papagianni, A. (2010). Multiplayer online games as educational tools: Facing new challenges in learning. Computers \& Education. 54(2): 498-505. doi: 10.1016/j.compedu.2009.09.001. [GS Search].

Pires, C., Navarro, D. \& Pires, V. (2015). Um Jogo Didático para Deteção de Problemas de Qualidade de Dados em Banco de Dados Relacionais. Revista Brasileira de Informática na Educação. 23(3): 98-112. doi: 10.5753/rbie.2015.23.03.98. [GS Search].

Pötter, H. e Schots, M. (2012). InspectorX: Um Jogo para o Aprendizado em Inspeção de Software. Anais do V Fórum de Educação em Engenharia de Software - FEES 2012, (pp. 01-08), Natal - $\quad$ RN, Brasil. rio.br/FEESArtigos/artigos/artigos_FEES11/fees11_05.pdf. [GS Search].

Rodriguez, C. L., Zem-Lopes, A. M., Marques, L. \& Isotani, S. (2015). Pensamento Computacional: transformando ideia em jogos digitais usando o Scratch. Anais do XXI Workshop de Informática na Escola - WIE 2015, (pp. 62-71), Maceió-AL, Brasil. doi: 10.5753/cbie.wie.2015.62. [GS Search].

Savi, R. Von Wangenheim, C. G. \& Borgatto, A. F. (2011). A Model for the Evaluation of Educational Games for Teaching Software Engineering. Anais do 25th Brazilian Symposium on Software Engineering, (pp. 194-203), São Paulo - SP, IEEE. doi: 10.1109/SBES.2011.27. [GS Search].

Schild, J., Walter, R. \& Masuch, M. (2010). Scrum ABC-Sprints: Adapting Scrum to Academic Game Development Courses. Proceedings of the Fifth International Conference on the Foundations of Digital Games, (pp. 187-194), Monterey, California. doi: 10.1145/1822348.1822373. [GS Search].

Schwaber, K., \& Sutherland, J. (2013). Guia do Scrum - Um guia definitivo para o Scrum: As Regras do Jogo. [GS Search].

Souza-Concilio L. \& Pacheco, B. (2013). Games and Learning Management Systems: A Discussion about Motivational Design and Emotional Engagement. Anais do XII Simpósio Brasileiro de Games e Entretenimento Digital - SBGames2013, (pp. 38-45), São Paulo SP. http://www.sbgames.org/sbgames2013/proceedings/cultura/Culture-6 full.pdf.

Sutherland, J. (2014). Scrum: a arte de fazer o dobro do trabalho na metade do tempo. São Paulo, SP:Leya. [GS Search]

Wendel, V., Gutjahr, M., \& Steinmetz, R. (2013). Designing collaborative multiplayer serious games. Education and Information Technologies, 18, 287-308. doi: 10.1007/s10639-0129244-6. [GS Search]. 